\title{
Immediate Effect of Serratus Posterior Inferior Muscle Direction Taping on Thoracolumbar Junction Rotation Angle During One Arm Lifting in the Quadruped Position
}

\author{
Nu-ri Kim ${ }^{1,2}$, BPT, PT, Sun-hee Ahn",3, PhD, PT, Gyeong-tae Gwak ${ }^{2,3}$, PhD, PT, Hwa-ik Yoo ${ }^{1,2}$, BPT, PT, \\ Oh-yun Kwon ${ }^{2,3}$, PhD, PT \\ ${ }^{1}$ Department of Physical Therapy, The Graduate School, Yonsei University, ${ }^{2}$ Laboratory of Kinetic Ergocise Based on Movement Analysis, \\ ${ }^{3}$ Department of Physical Therapy, College of Health Science, Yonsei University, Wonju, Korea
}

\author{
Article Info \\ Received June 28, 2021 \\ Revised July 18, 2021 \\ Accepted July 19, 2021 \\ Corresponding Author \\ Oh-yun Kwon \\ E-mail: kwonoy@yonsei.ac.kr \\ https://orcid.org/0000-0002-9699-768X
}

\section{Key Words}

Movement

Rotation

Serratus posterior inferior

\begin{abstract}
Background: The serratus posterior inferior (SPI) muscle originates from the spinous process of T11-L2 and inserts at the lower border of the 9-12th ribs. This muscle is involved in thoracolumbar rotation and stability. Several positions can be used to improve trunk stability; the quadruped position is a good position for easily maintaining a neutral spine. In particular, during one arm lifting, various muscles act to maintain a neutral trunk position, and the SPI is one of these muscles. If trunk stability is weakened, uncontrolled trunk rotation may occur at this time. Tape can be used to increase trunk stability. There have been no studies on the effect of taping applied to the SPI muscle on thoracolumbar junction (TL) stability.
\end{abstract}

Objects: This study compared the TU rotation angle between three different conditions (without taping, transverse taping, and SPI muscle direction taping).

Methods: Thirty subjects were recruited to the study (18 males and 12 females). The TU rotation angle was measured during one arm lifting in a quadruped position (ALQP). Two taping methods (transverse and SPI muscle direction taping) were applied, and the TU rotation angle was measured in the same movement.

Results: SPI muscle direction taping significantly reduced TU rotation compared to that without taping $(p<0.001)$ and with transverse taping $(p<0.001)$. There was a significant difference in the TU rotation angle between transverse taping and SPI muscle direction taping $(p<0.017)$.

Conclusion: SPI muscle direction taping reduces the TU rotation angle during ALQP. Therefore, SPI muscle direction taping is one method to improve TU stability and reduce uncontrolled TU rotation during ALQP.

\section{INTRODUCTION}

The thoracolumbar junction (TLJ) is a section from the thoracic spine to the lumbar spine. The facet joints of the thoracic vertebrae that are frontally oriented are changed to the lumbar vertebrae in the sagittal direction [1]. During rotation, the thoracic vertebrae are restricted by the ribs, and the upper lumbar vertebrae are restricted by facet joints that are sagittally oriented [1,2]. Therefore, trunk rotation occurs more frequently in the thoracic spine than in the lumbar spine, and the TLJ is in a relatively unstable portion [3-5]. Several authors have emphasized the stability of the TLJ to protect against injury or fracture [6,7]. The stability of the spine can be enhanced by intrinsic supports, such as muscle isometric contraction, and extrinsic supports, such as belts or taping [8-10]. Taping is an extrinsic support device that is a cheap and convenient method for improving stability and muscle function [11]. Taping can provide biomechanical support by improving neuromuscular facilitation and proprioception of the affected joint [12-14]. It can also increase specific joint stability according to the direction of tape attachment [15]. When taping is applied parallel to the muscle fiber, it can facilitate muscle function underneath the tape; when applied perpendicular to the muscle fiber, it can inhibit muscle action [16-18]. Taping is divided into elastic 
and non-elastic taping (NET). NET has stronger fixation than elastic taping because of its material properties [19]. Previous studies have investigated the benefits of NET for stability of the spine to motion, such as trunk flexion and extension; however, no study has numerically identified the effect of NET on trunk rotation [9,19,20]. Kang et al. [9] found that NET applied to the lumbar region provided lumbar stability and increased the range of motion of the hip during lumbar flexion. Kim et al. [12] reported that NETs in the lumbar spine promote proprioceptor awareness, provide spinal stiffness, prevent lumbar flexion, and maintain neutral trunk posture when sitting.

Trunk stability is improved in various positions, such as the double leg bridge in hook-lying, front plank, and alternating opposite arm-leg lifting in a quadruped position [21]. In particular, the quadruped position, in which hands and knees are placed on the table, can easily maintain a neutral spine position; therefore, it is recommended as an early stage of rehabilitation exercises [22-24]. In addition, trunk stability can be strengthened through various movements, such as lifting one arm or alternating opposite arm-leg lifting in a quadruped position [25-27]. When trunk rotational torque is generated during one arm lifting, various muscles maintain a neutral trunk position [28]. However, if trunk stability is insufficient to maintain the spine in a neutral position during arm lifting in a quadruped position (ALQP), uncontrolled movement, such as TLJ rotation, may occur. Uncontrolled movement is a dysfunction of movement that may result from muscle weakness [29]. This can lead to tissue stress, spinal loading, and pain [29]. Therefore, ALQP is a good test for assessing trunk stability [30].

The trunk rotation muscles of the back include the latissimus dorsi (LD), multifidus, longissimus, iliocostalis, rotatores breves and longi, and serratus posterior inferior (SPI) [28,31,32]. These muscles are located from the superficial to the deep layer of the back, respectively. Superficial muscles are primarily responsible for movement, while deep muscles are responsible for body stability $[33,34]$. There are some studies on the effect of taping applied to the erector spinae or multifidus located in deeper layers, but there are no studies on the effect of taping applied to the SPI on trunk stability $[35,36]$. The SPI, which is directed from the spinous processes of T11-L2 to the lower border of the 9-12th ribs, can lead to TLJ rotation by generating rotational torque [37]. In addition, the SPI is located in a deeper layer, passes through the TLJ, stabilizing the rib cage [38]. Therefore, we designed this study to identify whether SPI muscle direction taping can reduce uncontrolled TLJ rotation by improving stability during ALQP. If SPI muscle direction taping demonstrates an effect on reducing uncontrolled TLJ rotation, it may provide useful information for the management of TLJ instability.

Therefore, the purpose of this study was to compare the TLJ rotation angle between three different conditions (without taping, transverse taping, and SPI muscle direction taping). We hypothesized that SPI muscle direction taping would improve TLJ stability during ALQP.

\section{MATERIALS AND METHODS}

\section{Subjects}

For this cross-sectional study and repeated measures, 30 subjects (18 males and 12 females) participated in this study (Table 1). A total of subjects were volunteers and were recruited from advertisements. Based on pilot data (average trunk rotation angle between the two taping methods) gathered from five subjects, G*power software (ver. 3.1; University of Trier, Trier, Germany) was used to calculate the sample size of 21 or more needed to achieve a power of 0.80 and an effect size of 0.608 with an $\alpha$ level of 0.05 . We used a post-hoc analysis to investigate the actual power of the sample size. When 30 subjects were recruited, post-hoc analysis indicated an effect size of 0.998. Subjects were included if they met the following criteria: (1) no history of low back pain, and (2) as per Comerford, during one arm lifting at $150^{\circ}$ in a quadruped position, thoracic rotation was observed [29]. The exclusion criteria were as follows: (1) history of injury to or surgery in the upper extremity; (2) neurological, psychiatric, or musculoskeletal disorders; (3) allergic to tape $[12,16,39]$. The research protocol was approved by Yonsei University, Mirae Institutional Review Board (approval NO. 1041849-202101-BM-002-01). Before this study, the subjects were explained the study process and signed an informed consent form.

Table 1. Subject characteristics

\begin{tabular}{lc}
\hline Variables & Subjects \\
\hline Age $(\mathrm{y})$ & $29.0 \pm 8.2$ \\
Height $(\mathrm{cm})$ & $170.8 \pm 7.0$ \\
Mass $(\mathrm{kg})$ & $70.0 \pm 13.5$ \\
\hline
\end{tabular}

Values are presented as mean \pm standard deviation. 


\section{Instrumentation}

\section{1) Rotation measurement system}

Kinematic data of the rotation were measured using a Smart KEMA motion sensor (KOREATECH Co., Ltd., Seoul, Korea) (Figure 1A). The motion sensor contained a tri-axillar gyroscope, magnetometer, accelerometer, signal converter, and signal transmission sensor. The data from the motion sensor were recorded at sampling frequencies of $25 \mathrm{~Hz}$ and transmitted to an Android tablet using Smart KEMA software (KOREATECH Co., Ltd.) [40-42]. For the measurement, the motion sensor was attached to the holder of the rotation measurement system (RMS) (Figure 1B) [43]. We used the RMS to measure the TLJ rotation in the transverse plane during ALQP. During the operation, the motion sensor indicated a rotation angle in the $\mathrm{y}$-axis of the transverse plane.

\section{Taping Methods}

A 20-cm long 3M Soft Cloth Tape $(5 \mathrm{~cm} \times 10 \mathrm{~m}$; Daemyung Co., Ltd., Yangju, Korea) was used for taping [44]. Two different NET methods were applied to reduce uncontrolled TLJ rotation during ALQP. The two taping methods were transverse and SPI muscle direction taping. Transverse taping was applied to the TLJ (Figure 2A). The SPI muscle direction taping was applied in parallel to the SPI muscle fiber direction (from the lower border of the 9-12th ribs to the spinous processes of T11-L2) of the lifting arm side (Figure 2B). We applied taping in two layers to increase fixation.

\section{Procedures}

First, the subjects took a quadruped position with their hands under the shoulder and knees under the hip joint (Figure 3A). A target bar was placed on one individual arm, and the height was adjusted to $180^{\circ}$ of shoulder flexion [39]. Before measurement, the RMS attached to the motion sensor was placed on the floor and calibrated to $0^{\circ}$. Next, the bars of the RMS were adjusted to the width of the TLJ for each subject. We then identified that the angle of TLJ rotation was $0^{\circ}$ through the motion sensor. Finally, the subjects lifted one arm. When their arm touched the target bar, they held this position for three seconds (Figure 3B). By holding the test position, the motion sensor data were recorded at the TLJ rotation angle and represented numerically. Before testing, the trunk rota-
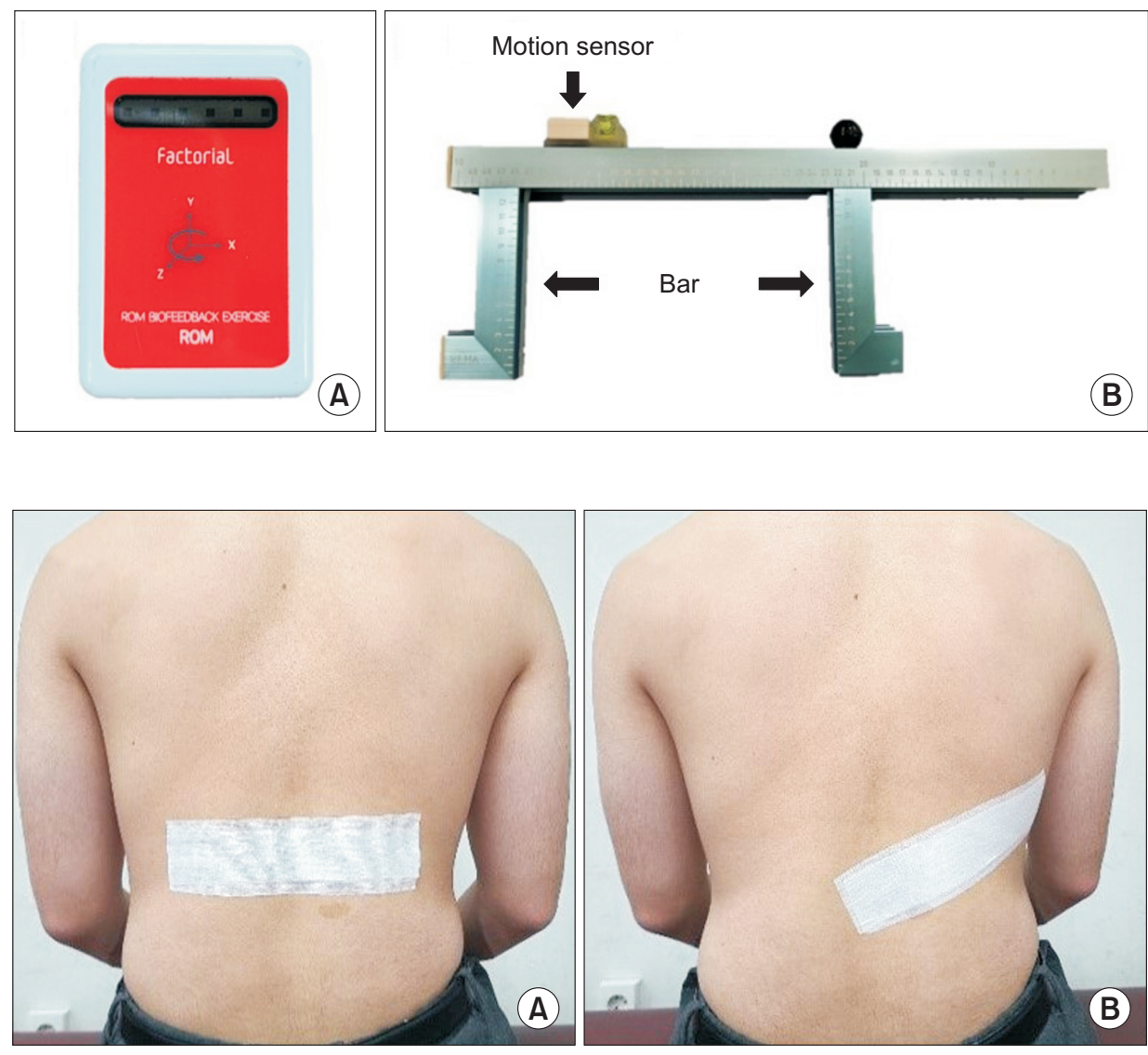

Figure 1. Instruments of thoracolumbar joint rotation angle measurement.
Figure 2. Taping methods. (A) Transverse taping, and $(B)$ right serratus posterior inferior muscle direction taping. 

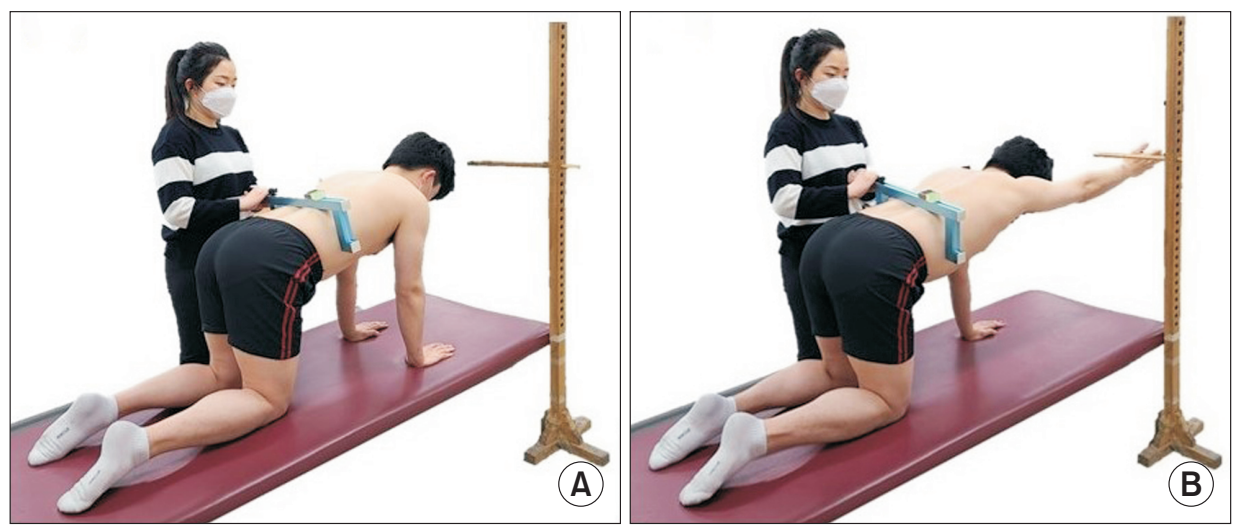

Figure 3. Measurement of thoracolumbar junction rotation angle. tion angle during ALQP was measured on both sides, and we determined the side with a greater TLJ rotation angle as the test side. Two taping methods were applied in a random order because the taping method sequence may affect TLJ rotation during ALQP. The order of the two taping methods was randomized using an online site (https://www.random.org/ sequences). In addition, we provided 5 minutes of rest between taping methods to prevent a learning effect.

\section{Statistical Analysis}

The data were analyzed using SPSS (version 25.0; IBM Co., Armonk, NY, USA), and the Kolmogorov-Smirnov test was performed to determine whether the data were normally distributed. The intraclass correlation coefficients (ICCs) $(3,1)$ and 95\% confidence intervals (CIs) were used to identify the intrarater reliability of the three trunk rotation angle measurements using the Smart KEMA motion sensor. Data are presented as mean \pm standard deviation. One-way analysis of variance with repeated measurements was used to compare the TLJ rotation angle between the three different conditions (without taping, transverse taping, SPI muscle direction taping). The significance level was set at $\mathrm{p}<0.05$. If a significant effect was found, Bonferroni correction was used with a statistical significance level of $\alpha=0.05 / 3=0.017$.

\section{RESULTS}

The ICCs for measuring the TLJ rotation angle were 0.974 (95\% CI, 0.946-0.987) without taping, 0.973 (95\% CI, 0.9440.987) for transverse taping, and 0.988 (95\% CI, 0.975-0.994) for SPI muscle direction taping (Table 2).

Table 3 shows the values and standard deviations of the TLJ rotation angle under three different conditions. Three different
Table 2. ICCs and $95 \% \mathrm{Cls}$ of three taping conditions

\begin{tabular}{lcc}
\hline \multicolumn{1}{c}{ Taping conditions } & ICC $(95 \% \mathrm{CI})$ & $\mathrm{p}$-value \\
\hline Without taping & $0.97(0.95-0.99)$ & $<0.001$ \\
Transverse taping & $0.97(0.94-0.99)$ & $<0.001$ \\
SPI muscle direction taping & $0.99(0.98-0.99)$ & $<0.001$ \\
\hline
\end{tabular}

ICC, intraclass correlation coefficient; $\mathrm{Cl}$, confidence interval; SPI, serratus posterior inferior.

conditions had a significant effect on the rotation angle of the TLJ (Table 3). Transverse taping $\left(12.29^{\circ} \pm 4.35^{\circ}\right)$ did not significantly reduce the TLJ rotation angle during ALQP compared to without taping $\left(13.34^{\circ} \pm 4.83^{\circ}\right)(\mathrm{p}>0.017$; Figure 4$)$. The SPI muscle direction taping method $\left(8.18^{\circ} \pm 4.00^{\circ}\right)$ showed a significant effect on reducing the TLJ rotation angle during ALQP compared to without taping $\left(13.34^{\circ} \pm 4.83^{\circ}\right)(\mathrm{p}<0.017$; Figure 4). In addition, the reduction of the TLJ rotation angle when SPI muscle direction taping was applied was significantly more effective than that with transverse taping $(\mathrm{p}<0.017$; Figure 4).

\section{DISCUSSION}

We investigated the immediate effect of two taping methods on uncontrolled TLJ rotation during ALQP. We found that SPI muscle direction taping was effective for reducing uncontrolled TLJ rotation angle and was more effective than transverse taping. There are some possible reasons for these results.

NET can increase joint stability through a fixation force. During ALQP, the trunk rotates in the direction of the lifting arm side because the supporting force is removed. In the case of taping attachment, SPI muscle direction taping was applied along the direction of the SPI muscle fibers on the lifting arm side, and transverse taping was applied from the lifting arm side to the opposite side. If a subject had more TLJ rotation on the right during ALQP, the SPI muscle direction taping was 
Table 3. TLJ rotation angle during one arm lifting in the quadruped position

\begin{tabular}{lccccc}
\hline & Without taping & Transverse taping & SPI muscle direction taping & Statistical value (F) & $p$-value \\
\hline TLJ rotation angle $\left({ }^{\circ}\right)$ & $13.34 \pm 4.83$ & $12.29 \pm 4.35$ & $8.18 \pm 4.00$ & 55.700 & $<0.001$ \\
\hline
\end{tabular}

$\mathrm{SPI}$, serratus posterior inferior; TLJ, thoracolumbar junction.

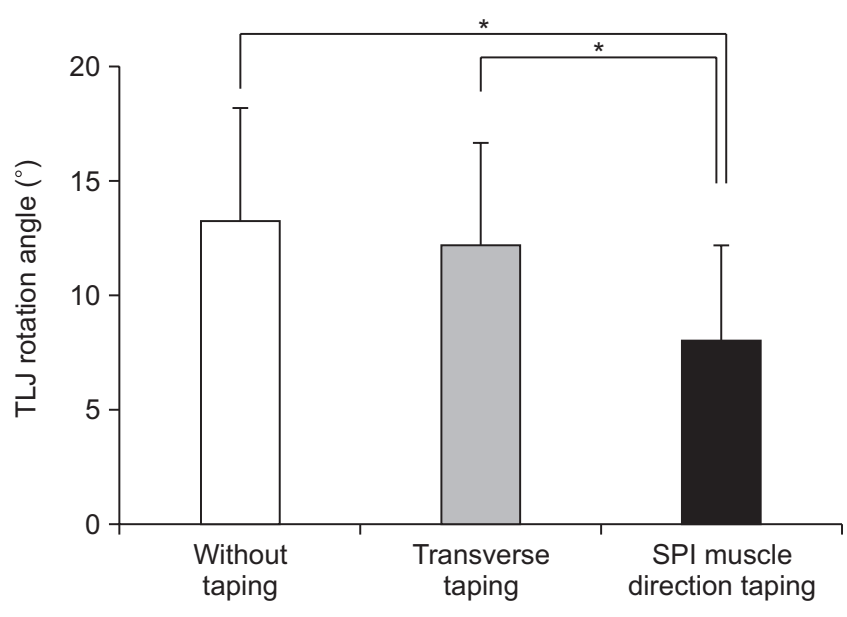

Figure 4. Comparison of thoracolumbar junction (TLJ) rotation angle between three different taping conditions. SPI, serratus posterior inferior.

along the right SPI muscle fibers (from the spinous processes of T11-L2 to the lower border of the 9-12th ribs), and the transverse taping was applied from right to left. By applying taping in a relatively oblique direction, the SPI muscle direction taping may reduce uncontrolled TLJ rotation due to the mechanical effect of counter rotation through the L2-9th rib direction in contrast to transverse taping.

In addition, NET can increase joint stability by improving proprioception to control joint alignment $[19,45,46]$. When TLJ rotation occurs, a neutral position is maintained by stabilizers and rotators, such as the LD, multifidus, and SPI [47]. This is consistent with the fact that if taping is applied parallel to the muscle fibers, it can facilitate muscle function [16-18]. SPI muscle direction taping may facilitate the SPI muscle, which is below the tape. In addition, uncontrolled TLJ rotation was reduced by promoting the LD, which is located close to the SPI muscle direction taping. The LD originates from the spinous process of T7-L5, thoracolumbar fascia, and iliac crest and inserts in the intertubercular groove of the humerus. In addition, it is located on the surface of the TLJ. Vleeming et al. [5] demonstrated that the posterior oblique sling is connected in the following order: gluteus maximus, thoracolumbar fascia, and contralateral LD. During ALQP, a coupled force is generated on the LD, which is the lifting side and gluteus maximus on the opposite side. This may increase TLJ stability during ALQP.
An important point of this study is that we identified a reduction in uncontrolled TLJ rotation angle with SPI muscle direction taping during ALQP. This study demonstrated that NET applied in the direction of SPI muscle fibers may be used to reduce uncontrolled TLJ rotation and increase TLJ stability during ALQP. In particular, SPI muscle direction taping significantly reduced uncontrolled TLJ rotation relative to that with transverse taping. Therefore, SPI muscle direction taping could be used to correct uncontrolled TLJ rotation angle during ALQP for TLJ stability exercise in reducing uncontrolled TLJ rotation.

This study had some limitations. The main limitation was the lack of electromyography to measure SPI activation. Therefore, further studies are needed to determine SPI muscle activation using needle electromyography to identify the effect of SPI muscle direction taping. Second, all subjects in this study were relatively young and healthy. The findings of this study might be different if the subjects had low back pain, since patients with low back pain have reduced ability to stabilize the spine than healthy subjects [48]. These results also cannot be generalized to older people. Further studies involving older people should be conducted.

\section{CONCLUSIONS}

We identified that the NET applied to SPI muscle fibers was effective in reducing the TLJ rotation angle during ALQP. Therefore, SPI muscle direction taping can reduce uncontrolled TLJ rotation and improve TLJ stability during ALQP. It has potential for clinical use as a method to improve TLJ stability.

\section{CONFLICTS OF INTEREST}

No potential conflict of interest relevant to this article was reported.

\section{AUTHOR CONTRIBUTIONS}

Concepualization: NK, GG, OK. Data curation: NK, OK. Formal analysis: NK, SA, GG, HY, OK. Funding acquisition: NK, 
OK. Investigation: NK. Methodology: NK, SA, GG, HY, OK. Project administration: NK, SA, GG, HY, OK. Supervision: NK, SA, GG, HY, OK. Validation: NK, HY, OK. Visualization: NK, SA, GG, HY, OK. Writing - original draft: NK, HY, OK. Writing review \& editing: NK, SA, HY, OK.

\section{ORCID}

Nu-ri Kim, https://orcid.org/0000-0001-7869-5939

Sun-hee Ahn, https://orcid.org/0000-0001-7660-8598

Gyeong-tae Gwak, https://orcid.org/0000-0003-1812-8910

Hwa-ik Yoo, https://orcid.org/0000-0002-5848-9633

\section{REFERENCES}

1. Fujii R, Sakaura H, Mukai Y, Hosono N, Ishii T, Iwasaki M, et al. Kinematics of the lumbar spine in trunk rotation: in vivo three-dimensional analysis using magnetic resonance imaging. Eur Spine J 2007;16(11):1867-74.

2. Singer KP, Day RE, Breidahl PD. In vivo axial rotation at the thoracolumbar junction: an investigation using low dose CT in healthy male volunteers. Clin Biomech (Bristol, Avon) 1989;4(3):145-50.

3. Chang CC, Chen YJ, Lo DF, Chen HT, Hsu HC, Lin RM. Palliative transpedicular partial corpectomy without anterior vertebral reconstruction in lower thoracic and thoracolumbar junction spinal metastases. J Orthop Surg Res 2015;10:113.

4. Oxland TR, Lin RM, Panjabi MM. Three-dimensional mechanical properties of the thoracolumbar junction. J Orthop Res 1992;10(4):573-80.

5. Vleeming A, Pool-Goudzwaard AL, Stoeckart R, van Wingerden JP, Snijders CJ. The posterior layer of the thoracolumbar fascia. Its function in load transfer from spine to legs. Spine (Phila Pa 1976) 1995;20(7):753-8.

6. Jull GA, Richardson CA. Motor control problems in patients with spinal pain: a new direction for therapeutic exercise. J Manipulative Physiol Ther 2000;23(2):115-7.

7. Wu Y, Chen CH, Tsuang FY, Lin YC, Chiang CJ, Kuo YJ. The stability of long-segment and short-segment fixation for treating severe burst fractures at the thoracolumbar junction in osteoporotic bone: a finite element analysis. PLoS One 2019;14(2):e0211676.

8. Ivancic PC, Cholewicki J, Radebold A. Effects of the abdominal belt on muscle-generated spinal stability and L4/L5 joint compression force. Ergonomics 2002;45(7):501-13.

9. Kang MH, Choi SH, Oh JS. Postural taping applied to the low back influences kinematics and EMG activity during patient transfer in physical therapists with chronic low back pain. J Electromyogr Kinesiol 2013;23(4):787-93.

10. Sharpe SR, Holt KG, Saltzman E, Wagenaar RC. Effects of a hip belt on transverse plane trunk coordination and stability during load carriage. J Biomech 2008;41(5):968-76.

11. Ouyang JH, Chang KH, Hsu WY, Cho YT, Liou TH, Lin YN. Nonelastic taping, but not elastic taping, provides benefits for patients with knee osteoarthritis: systemic review and metaanalysis. Clin Rehabil 2018;32(1):3-17.

12. Kim HA, Kwon OY, Ahn SH, Jeon IC, Choung SD. Effect of taping on lumbar kinematics and muscle activities during typing in individuals with nonspecific chronic low back pain. Phys Ther Korea 2015;22(1):93-102.

13. Simoneau GG, Degner RM, Kramper CA, Kittleson KH. Changes in ankle joint proprioception resulting from strips of athletic tape applied over the skin. J Athl Train 1997;32(2):141-7.

14. Thelen MD, Dauber JA, Stoneman PD. The clinical efficacy of kinesio tape for shoulder pain: a randomized, double-blinded, clinical trial. J Orthop Sports Phys Ther 2008;38(7):389-95.

15. Kang MH, Kim ER, Kim YG, Kim TH, Oh JS. The effects of lumbo-pelvic postural taping on gait parameters in patients with lumbar spinal stenosis. Clin Biomech (Bristol, Avon) 2013;28(9-10):956-60.

16. Bae SH, Lee YS, Kim KY. Does non-elastic taping application method affect the movement-related cortical potential and muscle activity. Int Inf Inst (Tokyo) 2018;21(8):2187-95.

17. Morrissey D. Proprioceptive shoulder taping. J Bodyw Mov Ther 2000;4(3):189-94.

18. Tobin S, Robinson G. The effect of McConnell's vastus lateralis inhibition taping technique on vastus lateralis and vastus medialis obliquus activity. Physiotherapy 2000;86(4):173-83.

19. Kuni B, Mussler J, Kalkum E, Schmitt H, Wolf SI. Effect of kinesiotaping, non-elastic taping and bracing on segmental foot kinematics during drop landing in healthy subjects and subjects with chronic ankle instability. Physiotherapy 2016;102(3):287-93.

20. Yin L, Wang L. Acute effect of kinesiology taping on postural stability in individuals with unilateral chronic ankle instability. Front Physiol 2020;11:192.

21. Butcher SJ, Craven BR, Chilibeck PD, Spink KS, Grona SL, Sprigings EJ. The effect of trunk stability training on vertical take- 
off velocity. J Orthop Sports Phys Ther 2007;37(5):223-31.

22. McGill SM. Low back exercises: evidence for improving exercise regimens. Phys Ther 1998;78(7):754-65.

23. Queiroz BC, Cagliari MF, Amorim CF, Sacco IC. Muscle activation during four Pilates core stability exercises in quadruped position. Arch Phys Med Rehabil 2010;91(1):86-92.

24. Stevens VK, Vleeming A, Bouche KG, Mahieu NN, Vanderstraeten GG, Danneels LA. Electromyographic activity of trunk and hip muscles during stabilization exercises in four-point kneeling in healthy volunteers. Eur Spine J 2007;16(5):7118.

25. García-Vaquero MP, Moreside JM, Brontons-Gil E, PecoGonzález N, Vera-Garcia FJ. Trunk muscle activation during stabilization exercises with single and double leg support. J Electromyogr Kinesiol 2012;22(3):398-406.

26. Kavcic N, Grenier S, McGill SM. Quantifying tissue loads and spine stability while performing commonly prescribed low back stabilization exercises. Spine (Phila Pa 1976) 2004; 29(20):2319-29

27. Yoon TL, Cynn HS, Choi SA, Choi WJ, Jeong HJ, Lee JH, et al. Trunk muscle activation during different quadruped stabilization exercises in individuals with chronic low back pain. Physiother Res Int 2015;20(2):126-32.

28. Ng JK, Parnianpour M, Richardson CA, Kippers V. Functional roles of abdominal and back muscles during isometric axial rotation of the trunk. J Orthop Res 2001;19(3):463-71.

29. Comerford M, Mottram S. Kinetic control: the management of uncontrolled movement. Chatswood: Elsevier; 2012.

30. Liemohn WP, Baumgartner TA, Gagnon LH. Measuring core stability. J Strength Cond Res 2005;19(3):583-6.

31. Lee LJ, Coppieters MW, Hodges PW. Differential activation of the thoracic multifidus and longissimus thoracis during trunk rotation. Spine (Phila Pa 1976) 2005;30(8):870-6.

32. Vilensky JA, Baltes M, Weikel L, Fortin JD, Fourie LJ. Serratus posterior muscles: anatomy, clinical relevance, and function. Clin Anat 2001;14(4):237-41.

33. Comerford MJ, Mottram SL. Movement and stability dysfunction--contemporary developments. Man Ther 2001;6(1):1526.

34. Haruyama K, Kawakami M, Otsuka T. Effect of core stability training on trunk function, standing balance, and mobility in stroke patients. Neurorehabil Neural Repair 2017;31(3):2409.

35. Kim DJ, Choi IR, Lee JH. Effect of balance taping on trunk stabilizer muscles for back extensor muscle endurance: a randomized controlled study. J Musculoskelet Neuronal Interact 2020;20(4):541-8.

36. Shin DY, Heo JY. The effects of kinesiotaping applied onto erector spinae and sacroiliac joint on lumbar flexibility. J Korean Phys Ther 2017;29(6):307-15.

37. Kumar S, Narayan Y, Zedka M. An electromyographic study of unresisted trunk rotation with normal velocity among healthy subjects. Spine (Phila Pa 1976) 1996;21(13):1500-12.

38. Muscolino JE. Know the body: muscle, bone, and palpation essentials. St. Louis: Mosby; 2013.

39. Yoon TL, Cynn HS, Choi SA, Choi WJ, Lee JH, Choi BS. Visual feedback using a smart-phone mirroring system influences trunk muscle activity and kinematics of the trunk and pelvis in healthy and chronic low-back pain groups during arm and leg lift in quadruped position. Isokinet Exerc Sci 2015;23(2): $117-25$

40. Ahn SH, Kwon OY, Hwang UJ, Jung SH, Kim HA, Kim JH. The association between genu recurvatum angle and the strength of the hip and knee muscles in standing workers. Work 2020;66(1):173-81.

41. Gwak GT, Ahn SH, Kim JH, Weon YS, Kwon OY. Prediction model for the risk of scapular winging in young women based on the decision tree. Phys Ther Korea 2020;27(2):1408.

42. Weon YS, Ahn SH, Kim JH, Gwak GT, Kwon OY. Comparison of knee muscle strength and ankle dorsiflexion range of motion between standing workers with and without patellofemoral pain syndrome. Phys Ther Korea 2020;27(4):241-9.

43. Jung SH, Kwon OY, Jeon IC, Hwang UJ, Weon JH. Reliability and criterion validity of measurements using a smart phonebased measurement tool for the transverse rotation angle of the pelvis during single-leg lifting. Physiother Theory Pract 2018;34(1):58-65.

44. Kwon DH, Lee SM, Kim HJ, Lee JS. Effect of microcurrent taping therapy on lower back pain. J Korean Med 2011;32(5): 114-25.

45. Choi SH, Lim CG. Immediate effects of ankle non-elastic taping on balance and gait ability in patients with chronic stroke: a randomized, controlled trial. J Manipulative Physiol Ther 2020;43(9):922-9.

46. Refshauge KM, Kilbreath SL, Raymond J. The effect of recurrent ankle inversion sprain and taping on proprioception at the ankle. Med Sci Sports Exerc 2000;32(1):10-5. 
47. Shah J, Tanwar T, Iram I, Aldabbas M, Veqar Z. Effect of increased lumbar lordosis on lumbar multifidus and longissimus thoracis activation during quadruped exercise in patients with chronic low back pain: an EMG study. J Appl Biomech
2020;36(6):436-43.

48. Panjabi MM. Clinical spinal instability and low back pain. J Electromyogr Kinesiol 2003;13(4):371-9. 